\title{
Fabrication and photoelectrochemical study of selenide and oxide heterostructures for solar hydrogen evolution
}

\author{
Xiaokang Wan ${ }^{1,2, *}$, Yunbo $\mathrm{Xu}^{1,2}$ and Tingyong Fang ${ }^{1,2}$ \\ ${ }^{1}$ School of Environment and Energy Engineering, Anhui Jianzhu University, Hefei, 230601, China \\ ${ }^{2}$ Key Laboratory of Huizhou Architecture in Anhui Province, Hefei, 230601, China
}

\begin{abstract}
We report the synthesis and photoelectrochemical (PEC) studies of a novel $\mathrm{CdSe} / \mathrm{BiVO}_{4}$ planar heterojunction photoelectrodes for photoelectrochemical water splitting fabricated by chemical bath deposition of $\mathrm{CdSe}$ on the spin-coated $\mathrm{BiVO}_{4}$ layers. Temperature and time of chemical bath deposition were investigated to obtain the optimal deposition condition. The optimized $\mathrm{CdSe} / \mathrm{BiVO}_{4}$ with enhanced photo absorption yielded a maximum photocurrent density of $2.48 \mathrm{~mA}$ under the irradiation of AM $1.5 \mathrm{G}$ $\left(100 \mathrm{~mW} / \mathrm{cm}^{2}\right)$ simulated solar light illumination, which is enhanced by 3.87 times compared to bare $\mathrm{BiVO}_{4}$.
\end{abstract}

\section{Introduction}

Photoelectrochemical water splitting for hydrogen production has attracted intensive efforts as a feasible solution for solar energy conversion since the 1970s in the situation of energy crisis and environmental issues ${ }^{[1-}$ 3]. Although much progress has been achieved, the energy conversion efficiency and stability of the materials remain the two main challenges. Metal oxides and metal (oxy)nitrides usually have satisfactory stability under experimental condition while the efficiencies of those are not high enough ${ }^{[4]}$. Metal sulphides show excellent efficiencies while they are not quite stable ${ }^{[5,6]}$. $\mathrm{TiO}_{2}$ is one of the first and most studied semiconductor materials. However, the poor ability of visible light utilization blocks its further development.

Since then, numerous metal oxides such as $\mathrm{WO}_{3}{ }^{[7-9]}$, $\mathrm{BiVO}_{4}$, and $\mathrm{Fe}_{2} \mathrm{O}_{3}{ }^{[10-12]}$ with visible light response have been investigated. $\mathrm{BiVO}_{4}$ shows the potential as one of the most promising candidate materials for photocatalytic water splitting because of its high activity and advantageous visible light absorption. However, the severe charge recombination and poor electron/hole conductivity hinder the further application ${ }^{[13]}$. Nevertheless, the visible light absorption range of $\mathrm{BiVO}_{4}$ is not wide, which can only utilize irradiation wavelength less than $520 \mathrm{~nm}$ from sunlight. Therefore, many strategies have been developed to promote the efficiency of metal oxides ${ }^{[14]}$.

Constructing the suitable heterojunction structure is an effective solution among the modification strategies ${ }^{[15}$, ${ }^{16]}$. Metal selenides such as CdSe have been widely used as sensitizers for their narrow band gaps and wide range absorption spectra. $\mathrm{TiO}_{2}$ and many other wide band gap metal oxides have been investigated to form heterojunction structures for enhanced light absorption and improved charge separation.
However, $\mathrm{BiVO}_{4}$ has been rarely sensitized with narrow band gap materials such as CdSe. In the present study, a facile method for the fabrication of planar heterostructure of $\mathrm{CdSe} / \mathrm{BiVO}_{4}$ films has been adopted and the structure resulted in enhanced photoelectrochemical performance. The physical and photoelectrochemical properties were investigated and the mechanism was also discussed in detail.

\section{Experimental Section}

\subsection{Preparation procedure}

Preparation of $\mathrm{BiVO}_{4}$ films. $\mathrm{BiVO}_{4}$ films on transparent conductive fluorine-doped tin oxide (FTO) substrates were synthesized by a polymer-assisted solgel method ${ }^{[17]}$. FTO coated glasses (TEC-15 $15 \Omega /$ sp) were cleaned by ultrasonic cleaning in acetone, ethanol and deionized water for $30 \mathrm{~min}$, respectively, and then dried under nitrogen stream. The precursors were prepared by adding EDTA (Ethylene Diamine Tetraacetic Acid) into $\mathrm{Bi}\left(\mathrm{NO}_{3}\right)_{3} \cdot 5 \mathrm{H}_{2} \mathrm{O}$ in nitric acid and $\mathrm{NH}_{4} \mathrm{VO}_{3}$ in in ammonia water, respectively, and then mixed the two solutions to obtain the $\mathrm{BiVO}_{4}$ precursor $(0.1 \mathrm{M}, 100 \mathrm{~mL}) .10 \mathrm{~g}$ of polyvinyl alcohol (PVA) was dissolved into $100 \mathrm{~mL}$ deionized water. The $\mathrm{BiVO}_{4}$ precursor and PVA solution were mixed $(\mathrm{V} / \mathrm{V}=1: 1)$ to obtain a colloidal solution. The colloidal solution was then spin-coated on FTO substrates $(3000 \mathrm{rpm}, 30 \mathrm{~s})$, dried at $120^{\circ} \mathrm{C}$ and then calcined at $450^{\circ} \mathrm{C}$ for $2 \mathrm{~h}$.

Chemical bath deposition of CdSe. Deposition of CdSe on $\mathrm{BiVO}_{4}$ films to form heterostructures was conducted by chemical bath deposition (CBD) method. $0.02 \mathrm{~mol}$ of Se powder was solved into $100 \mathrm{~mL}$ of $0.5 \mathrm{M}$ $\mathrm{Na}_{2} \mathrm{SO}_{3}$ aqueous solution. Then the Se solution was maintained at $70{ }^{\circ} \mathrm{C}$ and refluxed for $5 \mathrm{~h}$ with nitrogen as

\footnotetext{
* Corresponding author: wanxiaokang@ahjzu.edu.cn
} 
protection atmosphere to obtain solution. The solution was stored for further use under $60^{\circ} \mathrm{C} .0 .253 \mathrm{~g} \mathrm{KOH}$ was added into $50 \mathrm{~mL}$ of deionized water and stirred. $0.285 \mathrm{~g}$ of aminotriacetic acid was added after $\mathrm{KOH}$ completely dissolved into the solution. After $0.5 \mathrm{~h}$ reaction, $0.309 \mathrm{~g}$ of chromic nitrate was added. Then the solution was kept at reaction temperature for $0.5 \mathrm{~h}$ and $5 \mathrm{~mL}$ of $\mathrm{Na}_{2} \mathrm{SeSO}_{3}$ solution was added slowly. The as-prepared $\mathrm{BiVO}_{4}$ films glass was then put into the flask at a certain angle. Then the flasks were transfer to oven for chemical bath deposition. After reaction, the electrodes were taken out and rinsed with clean water and then dried under nitrogen stream. The prepared photoelectrodes are named as $\mathrm{CdSe} / \mathrm{BiVO}_{4}-70-6 \mathrm{~h}$.

\subsection{Photoelectrochemical measurements}

Photoelectrochemical and electrochemical measurements were carried out in a conventional three electrodes cell. with illumination from the backside and a saturated $\mathrm{Ag} / \mathrm{AgCl}$ as the reference electrode, with a CHI760D electrochemical workstation. Photocurrents were recorded under $100 \mathrm{~mW} / \mathrm{cm}^{2} \mathrm{AM} 1.5 \mathrm{G}$ irradiation with a $300 \mathrm{~W}$ xenon lamp as the white-light source in a $0.5 \mathrm{M}$ $\mathrm{Na}_{2} \mathrm{SO}_{3}$ aqueous electrolyte. Incident photon to current conversion efficiencies (IPCEs) were measured at $0.76 \mathrm{~V}$ vs. RHE in $0.5 \mathrm{M} \mathrm{Na} \mathrm{SO}_{3}$ solution with a monochromator. The potentials vs. $\mathrm{Ag} / \mathrm{AgCl}$ were converted to potentials vs. the reversible hydrogen electrode (RHE) by the following Nernst equation: $E_{\mathrm{RHE}}$ $=E_{\mathrm{Ag} / \mathrm{AgCl}}+0.059 \mathrm{pH}+E_{\mathrm{Ag} / \mathrm{AgCl}}^{\mathrm{o}}$, where $E_{\mathrm{Ag} / \mathrm{AgCl}}^{\mathrm{o}}=0.1976$ $\mathrm{V}$ at $25^{\circ} \mathrm{C}$.

\section{Results and discussion}

Fig. 1 shows the SEM images of $\mathrm{CdSe} / \mathrm{BiVO}_{4}$ films in different deposition conditions and bare $\mathrm{BiVO}_{4}$ for comparison. From the images, all the samples fabricated under various temperatures and time conditions show flat and smooth surfaces, which indicates that the combination of spin-coating and CBD methods works well. The CdSe particles are deposited onto $\mathrm{BiVO}_{4}$ films and the latter are covered as underlayer, which resulted into a planar heterojunction. When the reaction time is not sufficient (2h), the size of CdSe particles are relatively small. With the increase of deposition time, the particle sizes grow from $30 \mathrm{~nm}$ to more than $100 \mathrm{~nm}$. From the inset image (Fig. 1d), the thickness of CdSe of $8 \mathrm{~h}$ deposition can be estimated to be $500 \mathrm{~nm}$.
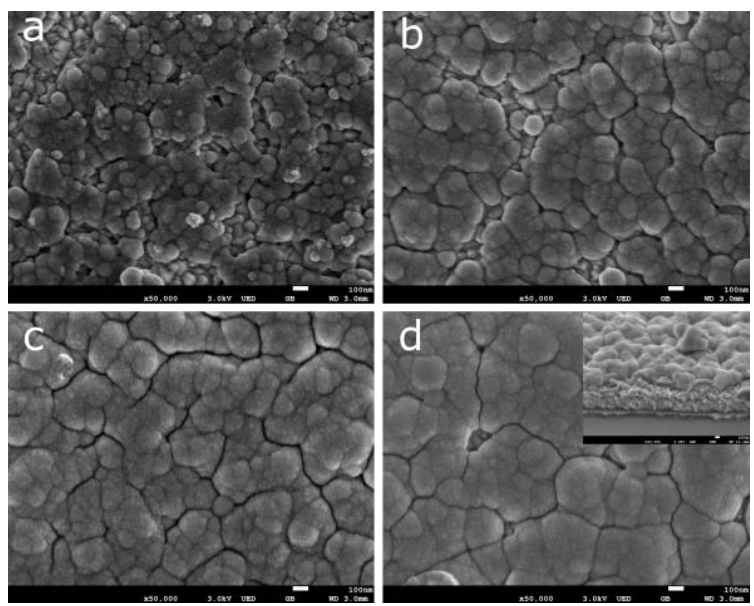

Figure 1. SEM images of the $\mathrm{CdSe} / \mathrm{BiVO}_{4}$ heterostructure photoelectrodes. (a) $70{ }^{\circ} \mathrm{C}, 2 \mathrm{~h}$, (b) $70{ }^{\circ} \mathrm{C}, 4 \mathrm{~h},(\mathrm{c}) 70{ }^{\circ} \mathrm{C}, 6 \mathrm{~h}$, (d) 70 ${ }^{\circ} \mathrm{C}, 8 \mathrm{~h}$.

The photocurrent densities of the various samples are shown in Fig. 2. The optimal temperature for high photocurrent densities are between 70 and $80{ }^{\circ} \mathrm{C}$. When the temperature is too much higher or lower, the activities decreases due to the aggregation of particles. The reaction time is more important than temperature. When the reaction time is short, the activities are all very low, while the reaction time increase to $\sim 6 \mathrm{~h}$, the activities show the best performances. Obviously, when reaction time are too long, the activities of the samples also decrease due to the larger sizes.

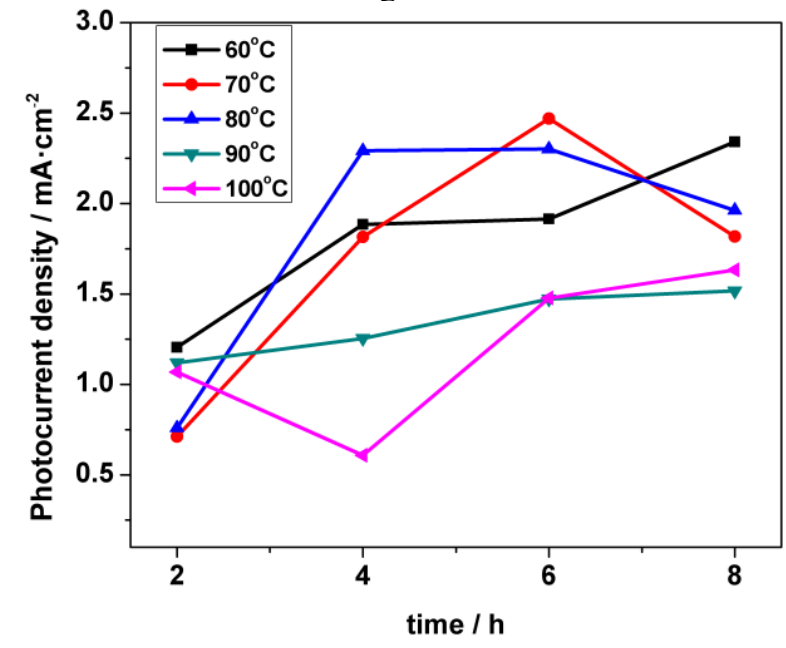

Figure 2. Photocurrent activities of the $\mathrm{CdSe} / \mathrm{BiVO}_{4}$ planar heterostructure photoelectrodes under various conditions.

In order to confirm the crystal structure of the hybrid films, XRD patterns are tested and shown in Figure 3. The patterns of monoclinic $\mathrm{BiVO}_{4}$ are also shown for comparison, which indicate that the film has good crystallinity and the patterns match well with JCPDS card NO.14-0688. After chemical bath deposition of $\mathrm{CdSe}$, the XRD signals show apparent changes. The new peaks at $25.4^{\circ}$ and $42.5^{\circ}$ are attributed to $\mathrm{CdSe}$ characteristic patterns. With the increasing deposition time, the signals intensities become much stronger, indicating the successful deposition of CdSe. 


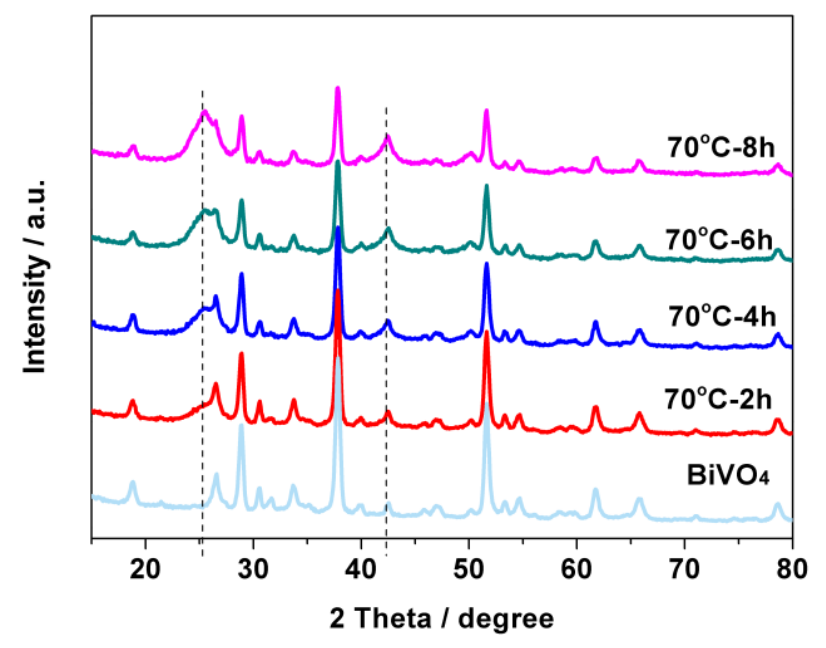

Figure 3. XRD patterns of $\mathrm{CdSe} / \mathrm{BiVO}_{4}$ heterostructure photoelectrodes prepared with different deposition time and the patterns of bare $\mathrm{BiVO}_{4}$ film as a reference.

As is well known, $\mathrm{BiVO}_{4}$ has a relatively narrow band gap of 2.0-2.1 eV. As a result, the photo absorbance has a great potential to be enhanced. The absorbance onset of $\mathrm{BiVO}_{4}$ is around $500 \mathrm{~nm}$ (Fig. 4), which indicates that only a small part of visible can be absorb and utilized by bare $\mathrm{BiVO}_{4}$ film. After deposition with $\mathrm{CdSe}$, the photoelectrodes shows remarkable improvement of absorbance. The absorbance onset was around $680 \mathrm{~nm}$. It is noteworthy that when the deposition time increases after $6 \mathrm{~h}$, the absorbance of the films remains unchanged, indicating that the amount of CdSe do not increase with the deposition time but only influence the particle size. As a result, the deposition time should be no more than $6 \mathrm{~h}$ for cost-effective consideration.

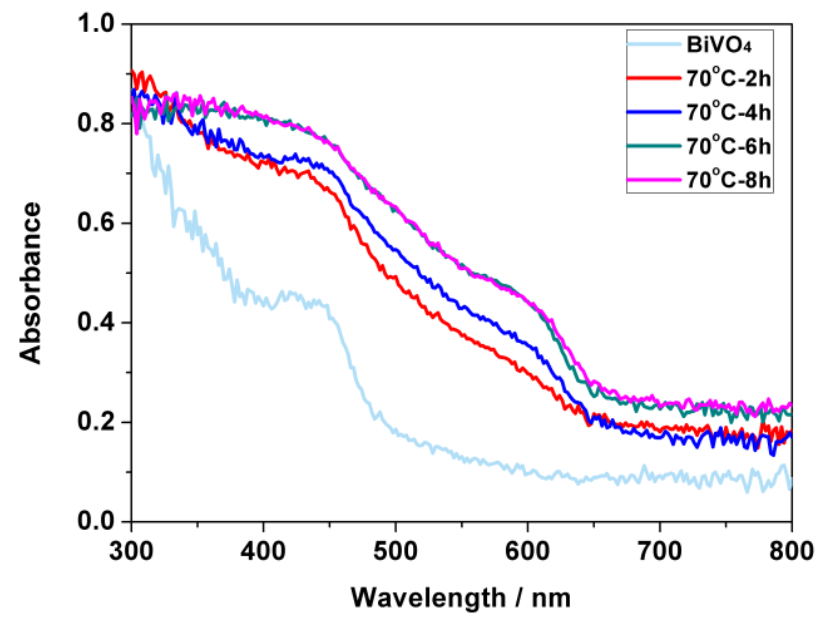

Figure 4. UV-Vis absorbance spectra of bare $\mathrm{BiVO}_{4}$ and $\mathrm{CdSe} /$ $\mathrm{BiVO}_{4}$ heterostructure photoelectrodes at different deposition time.

Fig. 5 shows the photocurrent-potential plots of the CdSe sensitized heterostructures and the plot of bare $\mathrm{BiVO}_{4}$ is also shown for comparison. All the samples show good irradiation response and the dark current can be neglected. The photocurrent density of bare $\mathrm{BiVO}_{4}$ is relatively low and the current onset locates at around 0.3 $\mathrm{V}$ vs. RHE. After CdSe deposition, the photocurrent densities show a remarkable increase. With the deposition time grow, the thicknesses of the hybrid films also increase, which lead to the increase of the light absorption and thus the photocurrent density increases consequently. And the best performance shows at the sample of $70{ }^{\circ} \mathrm{C}$ and $6 \mathrm{~h}$, which is about $2.48 \mathrm{~mA} / \mathrm{cm}^{2}$ and 3.87 times higher than that of bare $\mathrm{BiVO}_{4}$. However, the sample prepared at $70{ }^{\circ} \mathrm{C}$ and $8 \mathrm{~h}$ shows a decrease of photocurrent, which is ascribed to the aggregation of the larger particles. The significant enhancement of CdSe sensitization verifies the strategy of selenide and oxide heterostructure. On one hand, CdSe acts as the solar absorber, which can absorb much more light than bare $\mathrm{BiVO}_{4}$. On the other hand, the heterojunction structure is beneficial for the charge transfer, which promotes the PEC performance.

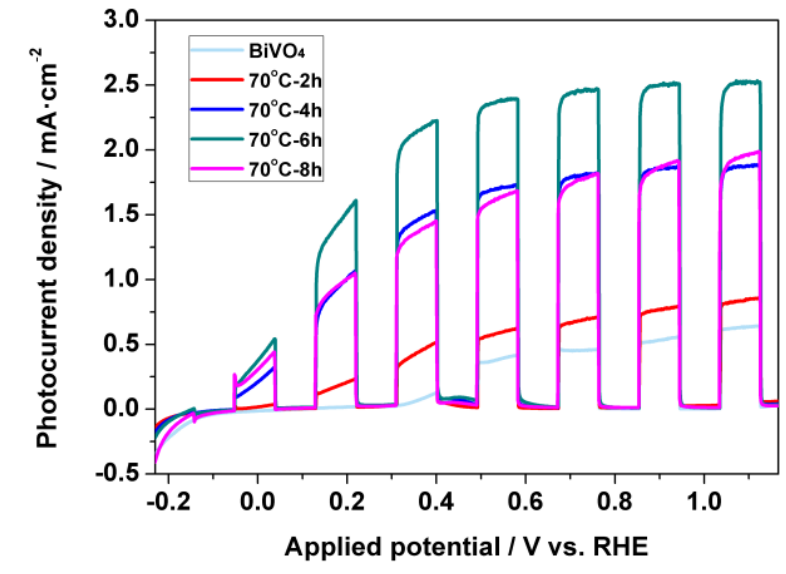

Figure 5. Photocurrent-potential plots of bare $\mathrm{BiVO}_{4}$ and $\mathrm{CdSe} / \mathrm{BiVO}_{4}$ heterostructure photoelectrodes.

Incident photon to current conversion efficiency (IPCE) data were also tested to evaluate the PEC performances of the samples under specific solar illumination wavelengths. The IPCE values were calculated by the equation:

$\mathrm{IPCE}=(1240 \mathrm{I}) /(\lambda \mathrm{P})$,

where $I$ is the photocurrent density measured at a specific wavelength, $\lambda$ is the wavelength of incident light and $\mathrm{P}$ is the power intensity of the light. Both the samples before and after sensitization show substantial visible light responses from Fig. 6. Bare $\mathrm{BiVO}_{4}$ shows a narrow visible light response till to $500 \mathrm{~nm}$. After $6 \mathrm{~h}$ CdSe deposition at $70{ }^{\circ} \mathrm{C}$, the visible light response red shift to $\sim 680 \mathrm{~nm}$ and the values are much higher. 


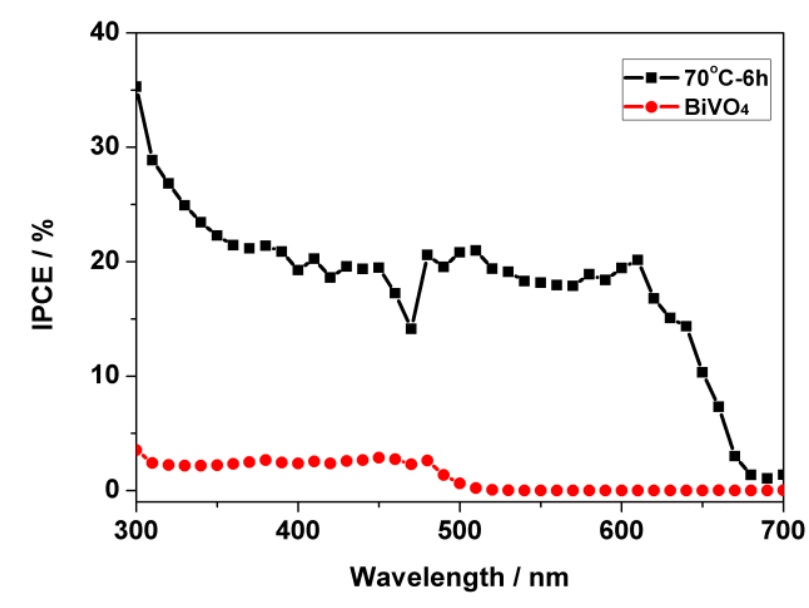

Figure 6. Incident photon to current conversion efficiency (IPCE) plots of the samples measured at $0.76 \mathrm{~V}$ vs. RHE in 0.5 $\mathrm{M} \mathrm{Na} 2 \mathrm{SO}_{3}$ solution.

\section{Conclusions}

Via the effective spin-coating of oxides layers and chemical bath deposition of selenides, the visible light material $\mathrm{BiVO}_{4}$ can be further sensitized to utilize broader range of solar irradiation. The successful fabrication of $\mathrm{CdSe} / \mathrm{BiVO}_{4}$ heterojunction photoanodes results in the enhanced PEC performance, which is ascribed to both the enhanced solar absorbance and the improved charge transport and transfer properties. The maximum photocurrent density of $2.48 \mathrm{~mA}$ is 3.87 times higher compared to bare $\mathrm{BiVO}_{4}$. From the physical and PEC measurements, the heterostructure proves to be an effective strategy for efficient PEC hydrogen production. The present work can provide beneficial guides and deep insights for the sensitization of visible light photoelectrochemical materials for PEC water splitting.

\section{Acknowledgement}

The authors gratefully acknowledge financial support from the Natural Science Foundation of the Anhui Higher Education Institutions of China (No. KJ2019A0760), the Science and Technology Major projects of Anhui Province (18030801106, 16030801118), and the Key Research and Development Plan of Anhui Province, Granted (201904a07020070).

\section{References}

1. T. Hisatomi, J. Kubota, and K. Domen, Chem. Soc. Rev. 43,22 (2014)

2. D. K. Lee, et al., Chem. Soc. Rev. 48,7 (2019).

3. M. Faraji, et al., Energ. Environ. Sci. 12, 1 (2019)

4. M. Volokh, et al., Angew. Chem. Int. Edit. 58,19 (2019)

5. M. Sandroni, et al., Energ. Environ. Sci. 11, 7 (2018)

6. M. Mollavali, C. Falamaki, and S. Rohani, Int. J. Hydrogen Energ. 43, 19 (2018)

7. S. J. Hong, et al., Energ. Environ. Sci. 4, 5 (2011)
8. L. Y. Huang, et al., Dalton T. 42, 24 (2013)

9. G. M. Wang, et al., Energ. Environ. Sci. 5, 3 (2012)

10. J. Xiong, et al., Int. J. Hydrogen Energ. 43, 31 (2018)

11. K. Sivula, F. Le Formal, and M. Gratzel, Chemsuschem. 4, 4 (2011)

12. Y. C. Ling, et al., Nano Lett. 11, 5 (2011)

13. X. K. Wan, et al., Phys. Chem. Chem. Phys. 18, 46 (2016)

14. H. W. Jeong, et al., J. Phys. Chem. C. 117, 18 (2013)

15. S. G. Kumar, and K. Rao, Appl. Surf. Sci. 391, (2017)

16. R. Adhikari, et al., J. Mater. Chem. A, 2018. 6(16)

17. X. K. Wan, M. T. Li, and L. J. Guo, Int. J. Hydrogen Energ. 38, 27 (2013) 